Original Research Paper

\title{
Inventory Models with Power Demand and Inventory-Induced Demand with Holding Cost Functions
}

\author{
${ }^{1}$ Rakesh Prakash Tripathi, ${ }^{2}$ Sarla Pareek and ${ }^{2}$ Manjit Kaur \\ ${ }^{1}$ Department of Mathematis, Graphic Era University, Dehradun, 248001, India \\ ${ }^{2}$ Department of Mathematics and Statistics, Banasthali University, Raj.-304022, India
}

\author{
Article history \\ Received: 20-11-2015 \\ Revised: 01-09-2016 \\ Accepted: 29-03-2017 \\ Corresponding Author: \\ Rakesh Prakash Tripathi \\ Department of Mathematics \\ Graphic Era University, \\ Dehradun, India \\ Email: tripathi_rp0231@rediffmail.com
}

\begin{abstract}
In real life customers are motivated to buy more if there is more availability of product. In this study, we develop inventory model for inventory dependent demand with different holding cost function. Mathematical formulations are discussed for two situations i.e., power demand rate with inventory dependent holding cost functions and inventory-induced demand rate with time and inventory dependent holding cost functions. The second order approximation is applied for exponential terms to find numerical values. Numerical examples are discussed to illustrate the models proposed in this study. The sensitivity analysis is given for optimal (minimum) solution with respect to key parameters is also discussed.
\end{abstract}

Keywords: Variable Holding Cost, Stock, Power Demand, Optimization, Time-Dependent

\section{Introduction}

In traditional Economic Order Quantity (EOQ) model, demand rate is considered as steady in nature. However, in reality the demand for physical products may be inventory, selling price or power-level dependent. The consumption rate for certain types of items, fluctuate with the on-hand inventory-level. Levin et al. (1972) discussed that large amount of products showed in a large shop will cause the buyer to purchase larger quantity. Silver and Peterson (1985), observed that "sales at the retails level tend to be proportional to stock displayed and a large amount of items displayed in a large shop will cause customers to purchase more". Gupta and Vrat (1986) were presented a model to minimize the cost with the assumption that stock-dependent consumption rate is a function of the initial stock-level for consumption environment. Baker and Urban (1988) developed an economic order quantity model for "a power stock induced demand pattern". After that Mandal and Phaujdar (1989) established a "production economic order quantity model for deteriorating items with uniform production and inventory-dependent demand". Padmanabhan and Vrat (1988) presented EOQ models for inventory induced selling rate with deteriorating items and rate of selling is assumed to be a function of stock level. Gerchak and Wang (1994) presented "an inventory models for corporate inventory-induced dependence of demand into various inventory control models and developed periodicreview inventory models with inventory level dependent demand". Urban (1995) investigated an inventory periods differ from the stock time demand by a given amount. Alfares (2007) established the "inventory policy for an item with a inventory dependent demand rate and a storage time dependent holding cost, the holding cost per unit of the items per unit time is assumed to be an inventory function of the time spent in storage". Datta and Pal (1990) considered "deterministic inventory system with inventory induced demand rate up to a contain level and a constant demand for the rest of the cycle with an infinite time horizon". Pal et al. (1993) presented an inventory model for inventory induced demand and items deteriorate at a constant rate over time. Hwang and Hahn (2000) established an EOQ model for inventory-induced demand rate and a certain expiry date.

Several researchers considered that the holding cost is always constant. However, holding cost is timedependent for few inventory models. Ray and Chaudhuri (1997) considered "the time value of money in to account by analyzing an inventory system with inventory induced demand rate and shortages". Giri et al. (1996) presented "an inventory model for deteriorating items with shortages". Two research papers were developed by (Chang et al., 2010; Yang et al., 2010) related to the inventory-dependent demand rate. 
During the last two decades, several researchers have been considered that the integration of production and EOQ model and the consignment of inventory. In this direction, Banerjee (1986) established "a Joint economic lot-size model and assumed that the supplier followed a lot-for-lot shipment policy with the retailer". Goyal (1988) further generalized Bannerjee's model considering a batch that consists of a number of equal-sized shipments, but the production of the batch had to be finished before the shipment could start. Hill (2000) established "an optimal two-stage lot sizing and inventory batching policies". Teng et al. (2011) considered an EOQ model for inventory-dependent demand under progressive payment scheme. Goyal and Chang (2009) established "an ordering-transfer model to find the retailer's optimal order quantity and the number of transfer per order from warehouse to display area". Yang and Wee (2003) considered "an integrated multi-lot-size production inventory model for deteriorating items". Law and Wee (2006) established "an integrated production-inventory model for ameliorating and deteriorating items taking account of time discounting". Other papers related to this area are (Viswanathan, 1998; Goyal and Nebebe, 2000; Chiang, 2001; Siajadi et al., 2006; Hou, 2006; Ghiami et al., 2013; Yang, 2014; Jiangtao et al., 2013; Soni, 2013) and others.

This paper, we present holding cost as two different functional form of demand rate (i.e., (i) inventory and (ii) time and inventory dependent). The main objective of this paper is to find minimum total inventory cost per cycle time. In the section 2 , the assumption and notation related to this study are presented. Then, we provide mathematical formulation for two different circumstances and show that the total inventory cost is minimum (i.e., total inventory cost is convex function with respect to cycle time). We also discuss numerical examples to validate the model. A sensitivity analysis is provided with respect to parameters of the system. At the last, conclusion and future research are given.

\section{Assumption and Notations}

\section{Assumptions}

The following assumptions are considered to construct the mathematical formulation:

- The demand rate is (i.e., $R\left((I(t))=\alpha\left\{I(t)^{\beta}\right\}\right.$ ), for model I and stock-dependent (i.e., function of stocklevel depend on demand for model II

- Shortage is not allowed

- Lead time is negligible

- The inventory system involves only one item

- Only one item is considered for inventory system

\section{Notations}

In addition the following notations are considered in the whole manuscript:

$$
\begin{array}{ll}
k & =\text { Ordering cost per order } \\
\alpha & =\text { Constant annual demand rate } \\
I(t) & =\text { Inventory level at any instant ' } t \\
H & =\text { Holding cost parameter/time } \\
T & =\text { Replenishment time } \\
B & =\text { Demand elasticity, } 0<\beta<1 \\
T I C & =\text { Optimal total inventory cost/time } \\
T I C_{1}{ }^{*} & =\text { Minimum total inventory cost per unit time } \\
& \text { for model one } \\
T I C_{2}{ }^{*}= & \text { Optimal total inventory cost/time for model } \\
T=T_{1}{ }^{*}= & \text { Optimal cycle time for model I } \\
T=T_{2}{ }^{*}= & \text { Optimal cycle time for model II } \\
Q & =\text { Order quantity } \\
Q=Q_{1}{ }^{*}= & \text { Optimal order quantity for model } i \\
q=q_{2}{ }^{*}= & \text { Optimal order quantity for model II }
\end{array}
$$

\section{Mathematical Formulation}

The main objective of this work is to minimize the total inventory cost/time, which contains two components i.e., (i) ordering cost $(k)$ and (ii) Holding Cost (HC). The holding cost is the integral of $h . I(t) d t$ and demand rate $\alpha\left\{I(t)^{\beta}\right\}$ for model I and integral of h.t. $I(t) d t$; demand rate is $\{\alpha+\beta I(t)\}$ for model II:

\section{Case I: Power Dependent Demand and Holding Cost Function}

In this model, the total inventory cost/time is expressed as:

$$
T I C=\frac{k}{T}+\frac{1}{T} \int_{0}^{T} h \cdot I(t) d t
$$

For this model the rate of inventory is considered to be inventory level decrease, the rate of variation of inventory level is given by:

$$
\frac{d I(t)}{d t}=-\alpha\{I(t)\}^{\beta}, \alpha>0,0<\beta<1,0 \leq t \leq T
$$

With the conditions $I(T)=0$.

The solution of Equation 2 with the above condition is given by is given by:

$$
I(t)=\{\alpha(1-\beta)(T-t)\}^{1 /(1-\beta)}, 0<\beta<1
$$

and the corresponding order quantity is:

$Q=\{\alpha(1-\beta) T\}^{1 /(1-\beta)}$ 
Solving Equation 4 for $T$, we have:

$T=\frac{Q^{(1-\beta)}}{\alpha(1-\beta)}$

Using Equation 3 in Equation 1 and solving, we get:

$T I C=\frac{k}{T}+\frac{h\{\alpha(1-\beta)\}^{1 /(1-\beta)} T^{1 /(1-\beta)} \cdot(1-\beta)}{(2-\beta)}$

Using Equation 5 and 6, becomes:

$T I C=\frac{k \alpha(1-\beta)}{Q^{(1-\beta)}}+\frac{h Q(1-\beta)}{(2-\beta)}$

Differentiating Equation 7 w.r.t. $Q$ two times, we get:

$\frac{d(T I C)}{d Q}=\frac{h(1-\beta)}{(2-\beta)}-k \alpha(1-\beta)^{2} Q^{(\beta-2)}$

$\frac{d^{2}(T I C)}{d Q^{2}}=k \alpha(1-\beta)^{2}(2-\beta) Q^{(\beta-3)}>0$

The necessary and sufficient condition that $Q=Q_{1}{ }^{*}$ is minimum is that $\frac{d(T I C)}{d Q}=0$ and $\frac{d^{2}(\text { TIC })}{d Q^{2}}>0$. The minimum order quantity is obtained by solving $\frac{d(T I C)}{d Q}=$ 0 , we get:

$Q=Q_{1}^{*}=\frac{\left\{k \alpha(1-\beta)(2-\beta\}^{1 /(2-\beta)}\right.}{h^{1 /(2-\beta)}}$

and the corresponding optimal (minimum) TIC is:

$T I C_{1}^{*}=h^{(1-\beta) /(2-\beta)} \cdot\{k \alpha(1-\beta)(2-\beta)\}^{1 /(2-\beta)}$

Model II: Inventory Dependent Demand Rate and Time Dependent Holding Cost Function

The demand rate is considered to be the rate of inventory-induced dependent decrease in this model, the rate of variation of inventory level is given by:

$\frac{d I(t)}{d t}=-\{\alpha+\beta I(t)\}, \alpha>0,0<\beta<1,0 \leq t \leq T$

Under initial conditions $I(T)=0$

The solution of Equation 12 with the above initial condition is:

$$
I(t)=\frac{\alpha}{\beta}\left\{e^{\beta(T-t)}-1\right\}
$$

and the order quantity is:

$Q=\mathrm{I}(0)=\frac{\alpha}{\beta}\left(e^{\beta T}-1\right)$

The Equation 14, can be rewritten as:

$T=\frac{1}{\beta} \log (1+\beta Q / \alpha)$

Total inventory cost/time is:

TIC $=\frac{k}{T}+\frac{1}{T} \int_{0}^{T} h \cdot t \cdot I(t) d t$

TIC $=\frac{k}{T}-\frac{h \alpha}{\beta^{2}}-\frac{h \alpha}{\beta^{3} T}+\frac{h \alpha}{T \beta^{3}} e^{\beta T}-\frac{h T \alpha}{2 \beta}$

Using Equation 15 and 17, becomes:

TIC $=\frac{k \beta}{\log (1+\beta Q / \alpha)}$

$-\frac{h \alpha}{\beta^{2}}+\frac{h Q}{\beta \log (1+\beta Q / \alpha)}-\frac{h \alpha}{2 \beta^{2}} \log (1+\beta Q / \alpha)$

The optimal (minimize) value of $Q$ is obtained by putting, $\frac{d(T I C)}{d Q}=0$, provided $\frac{d^{2}(T I C)}{d Q^{2}}>0$ The minimum value of $Q=Q_{2}{ }^{*}$ are $\frac{d(T I C)}{d Q}=0$. But it is difficult to handle Equation 18 to find closed form solution. The second order approximation is used for log arithmetic term and again using second order Taylor's series approximation, Equation 18 reduces to:

TIC $=k \alpha\left(\frac{1}{Q}+\frac{\beta}{2 \alpha}+\frac{\beta^{2} Q}{4 \alpha^{2}}\right)+\frac{h Q^{2}}{2 \alpha}$

[Note that the approximations are valid for $\beta T<1$ and $(\beta Q) / \alpha<1$. The second order approximation for $\log$ arithmetic term and then Taylor's series approximation, is given by:

$\log \left(1+\frac{\beta Q}{\alpha}\right)=\frac{\beta Q}{\alpha}-\frac{\beta^{2} Q^{2}}{2 \alpha^{2}}$,

$\frac{\alpha}{\beta Q}\left(1-\frac{\beta Q}{2 \alpha}\right)^{-1}=\frac{\alpha}{\beta}\left(\frac{1}{\mathrm{Q}}+\frac{\beta}{2 \alpha}+\frac{\beta Q}{4 \alpha^{2}}\right)$

and

$T=\frac{1}{\beta} \log (1+\beta Q / \alpha) \approx \frac{Q}{\alpha}\left(1-\frac{\beta Q}{2 \alpha}\right)$, approximately]. 
Differentiating Equation 19, with respect to $Q$ two times, we get:

$$
\frac{d(T I C)}{d Q}=k \alpha\left(-\frac{1}{Q^{2}}+\frac{\beta^{2}}{4 \alpha^{2}}\right)+\frac{h Q}{\alpha}
$$

and:

$$
\frac{d^{2}(T I C)}{d Q^{2}}=\frac{2 k \alpha}{Q^{3}}+\frac{h}{\alpha}>0
$$

The optimal (minimum) $Q=Q_{2} *$ is obtained by solving $\frac{d(T I C)}{d Q}=0$, we get:

$4 h Q^{3}+k \beta^{3} Q^{2}-4 k \alpha^{2}=0$

The optimal (minimum) order quantity value $Q=Q_{2} *$ is obtained by solving Equation 22 for $Q$ and putting $Q=Q_{2}$ * in Equation 19, the corresponding optimal (minimum) total inventory cost $T I C=T I C_{2}$ * is obtained.

\section{Numerical Examples}

In this section the present study provides the following numerical examples to validate the results are illustrated in the above section 3:

Example 1: Case I: Consider the inventory elements such as $\alpha=600$ units/year, $k=\$ 500 /$ order, $\beta=0.1, h=$ 1. We obtain.

$Q=Q_{1}^{*}=1012.336$ units, $T=T_{1} *=0.938423$ year and $T I C=T I C_{1} *=\$ 1012.335$.

Example 2: Case II: Let $\alpha=6000$ units per year, $k=$ $\$ 500 /$ order, $\beta=0.1, h=10$. We obtain $Q=Q_{2} *=1016.4$ units, $T=T_{2}{ }^{*}=0.1986233$ year and $T I C=T I C_{2} *=$ $\$ 3724.57$.

\section{Sensitivity Analysis}

In this section, we introduce sensitivity analysis with the variation of different parameters. Let us take the parameter values of the inventory system as Sensitivity analysis is performed by varying parameters, the effect of key parameters ' $h$ ' ' $k$ ' and ' $\beta$ ' on the optimal solution, the set of values of ' $h$ ', ' $k$ ' and ' $\beta$ ' are assumed to be ' $h$ ' $=1,5,10,-----, 80$, ' $\beta$ ' $=$ $0.2,0.3,0.4,0.5$. and ' $k$ ' $=510,530,550,580$.

The following managerial phenomena can be obtained from Table 1 and 2:

- From Table 1a, we see that when holding cost parameter increases, $Q_{1}{ }^{*}$ decreases and $T I C_{1}{ }^{*}$ increases. That is, changing ' $h$ ' causes a opposite change in $Q_{1}{ }^{*}$ and positive change in $T I C_{1}{ }^{*}$

- From Table 1a, we see that, if holding cost parameter increases $Q_{1}$ * decreases and increase in total inventory cost $T I C_{1}{ }^{*}$, keeping $\beta$ constant

- From Table $1 \mathrm{~b}$, we see that increase of $\beta$ results, increase in optimal order quantity $Q 1^{*}$ and total inventory cost $T I C_{1}{ }^{*}$. That is, change ' $\beta$ ' causes positive change in $Q_{1}{ }^{*}$ and $T I_{C 1}$ *, keeping $h$ constant

- From Table 1c, we see that increase of holding cost parameter $h$ results decrease in optimal order quantity $Q_{1}{ }^{*}$ and increase in total cost $T I C_{1}$ *, keeping $k$ constant

- From Table 1c, If holding cost parameter $h$ increases, $Q_{2}{ }^{*}$ and $T I C_{2}{ }^{*}$ will decrease, keeping $k$ constant. That is, changing ' $h$ ' causes a positive change in $Q_{1}{ }^{*}$ and $T I C_{1}{ }^{*}$, keeping k constant

- $\quad$ From Table 1c, we observe that when ordering cost ' $k$ ' increases, the optimal order quantity $Q_{1} *$ and total inventory cost $T I C_{1}{ }^{*}$, both will increase, keeping holding cost parameter $h$ constant. That is, change in ' $k$ ' causes $Q_{1}{ }^{*}$ and $T I C_{1}{ }^{*}$, keeping $h$ constant

- From Table 2a, we see that increase of holding cost parameter results increase in optimal order quantity $Q_{2}{ }^{*}$ and total inventory cost $T I C_{2}{ }^{*}$

- $\quad$ From Table 2a, we see that increase of $k$ leads increase in order quantity $Q_{1}{ }^{*}$ and total inventory $\cos t T_{I} C_{2}$ *

- From Table 2b, we see that increase in initial demand $\alpha$ results increase in optimal order quantity $Q_{2}{ }^{*}$ and total inventory cost $T I C_{2}{ }^{*}$. That is change in $\alpha$ causes positive change in $Q_{2}{ }^{*}$ and $T I C_{2}{ }^{*}$

- From Table $2 \mathrm{~b}$, we see that increase in $\beta$ results increase in optimal total inventory cost $T I C_{2} *$ while optimal order quantity $Q_{2}{ }^{*}$ approximately constant. That is change in $\beta$ causes positive change in $T I C_{2}{ }^{*}$ and no change in $\mathrm{Q}_{2}{ }^{*}$

Table 1. (a) Values of optimal values of $T=T_{1} *, Q=Q_{1} *$ and $T I C=T I C_{1} *$ for different values of ' $h$ ', taking remaining parameters same as in example 1

\begin{tabular}{llllllll}
\hline$h$ & $Q_{1}{ }^{*}$ & $T_{1}{ }^{*}$ & $T I C_{1}{ }^{*}$ & $h$ & $Q_{1}{ }^{*}$ & $T_{1}{ }^{*}$ & $T I C_{1}{ }^{*}$ \\
\hline 5 & 433.956 & 0.437832 & 2169.78 & 40 & 145.256 & 0.163503 & 5810.257 \\
10 & 301.306 & 0.315293 & 3013.068 & 50 & 129.160 & 0.147103 & 6458.031 \\
15 & 243.405 & 0.260197 & 3651.074 & 60 & 117.342 & 0.134932 & 7040.558 \\
25 & 186.023 & 0.204275 & 4650.578 & 70 & 108.198 & 0.125430 & 7573.884 \\
35 & 155.832 & 0.174179 & 5454.130 & 80 & 100.855 & 0.117742 & 8068.421 \\
\hline
\end{tabular}


Table 1. (b) Variation of optimal values of order quantity $Q=Q_{1} *$, cycle time $T=T_{1} *$ and total inventory cost $T I C=T I C_{1} *$ with the variation of parameter ' $h$ ' and demand elasticity ' $\beta$ ', keeping all the remaining elements same as in example 1

\begin{tabular}{llllll}
\hline$h \downarrow$ & $\beta \rightarrow$ & 0.2 & 0.3 & 0.4 & 0.5 \\
\hline \multirow{3}{*}{30} & $Q_{1}{ }^{*}$ & 204.257 & 249.678 & 308.262 & 383.155 \\
& $T_{1}{ }^{*}$ & 0.09399 & 0.0556 & 0.03114 & 0.01631 \\
35 & $T I C_{1}{ }^{*}$ & 6128.05 & 7491.11 & 9247.85 & 11494.6 \\
& $Q_{1}{ }^{*}$ & 187.503 & 228.034 & 279.948 & 345.735 \\
& $T_{1}{ }^{*}$ & 0.08777 & 0.05219 & 0.02939 & 0.01549 \\
40 & $T I C_{1}{ }^{*}$ & 6562.61 & 7981.2 & 9798.19 & 12100.7 \\
& $Q_{1}{ }^{*}$ & 174.097 & 210.808 & 257.533 & 316.287 \\
& $T_{1}{ }^{*}$ & 0.08271 & 0.04939 & 0.02796 & 0.01482 \\
45 & $T I C_{1}{ }^{*}$ & 6963.87 & 8432.32 & 10301.3 & 12651.5 \\
& $Q_{1}{ }^{*}$ & 163.07 & 196.697 & 239.256 & 292.402 \\
& $T_{1}{ }^{*}$ & 0.07849 & 0.04705 & 0.02675 & 0.01425 \\
50 & $T I C_{1}{ }^{*}$ & 7338.13 & 8851.36 & 10766.5 & 13158.1 \\
& $Q_{1}{ }^{*}$ & 153.798 & 184.876 & 224.008 & 272.568 \\
& $T_{1}{ }^{*}$ & 0.0749 & 0.04506 & 0.02571 & 0.01376 \\
55 & $T I C_{1}{ }^{*}$ & 7689.92 & 9243.82 & 11200.4 & 13628.4 \\
& $Q_{1}{ }^{*}$ & 145.867 & 174.796 & 211.054 & 255.788 \\
& $T_{1}^{*}$ & 0.0718 & 0.04332 & 0.02481 & 0.01333 \\
& $T I C_{1}{ }^{*}$ & 8022.67 & 9613.81 & 11608 & 14068.3 \\
& $Q_{1}{ }^{*}$ & 138.983 & 166.075 & 0.02401 & 241.372 \\
& $T_{1}{ }^{*}$ & 0.06907 & 0.0418 & 11993 & 0.01295 \\
& $T I C_{1}{ }^{*}$ & 8339 & 9964.5 & 14482.3 \\
\hline
\end{tabular}

Table 1. (c) Variation of optimal solution of $Q=Q_{1}{ }^{*}, T=T_{1} *$ and $T I C=T I C_{1}$ * with the variation of holding cost parameter ' $h$ ' and ordering cost ' $k$ ', taking remaining parameters same as in example 1

\begin{tabular}{llllll}
\hline$h \downarrow$ & $k \rightarrow$ & 510 & 530 & 550 & 580 \\
\hline \multirow{3}{*}{30} & $Q_{1}{ }^{*}$ & 170.773 & 174.266 & 177.696 & 182.733 \\
& $T_{1}{ }^{*}$ & 0.18914 & 0.19262 & 0.19603 & 0.20102 \\
& $T I C_{1}{ }^{*}$ & 5123.19 & 5227.97 & 5330.89 & 5482 \\
& $Q_{1}{ }^{*}$ & 157.465 & 160.685 & 163.849 & 168.646 \\
& $T_{1}{ }^{*}$ & 0.17582 & 0.17905 & 0.18222 & 0.18702 \\
40 & $T I C_{1}{ }^{*}$ & 5511.27 & 5623.99 & 5734.71 & 5897.27 \\
& $Q_{1}{ }^{*}$ & 146.778 & 149.78 & 152.729 & 157.058 \\
& $T_{1}{ }^{*}$ & 0.16504 & 0.16808 & 0.17105 & 0.17541 \\
45 & $T I C_{1}{ }^{*}$ & 5871.13 & 5991.21 & 6109.15 & 147.618 \\
& $Q_{1}{ }^{*}$ & 137.956 & 140.777 & 143.549 & 0.16589 \\
& $T_{1}{ }^{*}$ & 0.15609 & 0.15896 & 0.16177 & 6642.8 \\
50 & $T I C_{1}{ }^{*}$ & 6208 & 6334.97 & 1354.23 & 139.655 \\
& $Q_{1}{ }^{*}$ & 130.514 & 133.183 & 0.1539 & 0.15782 \\
& $T_{1}{ }^{*}$ & 0.12028 & 0.15122 & 6790.25 & 6982.73 \\
55 & $T I C_{1}{ }^{*}$ & 6525.69 & 6659.15 & 129.161 & 132.822 \\
& $Q_{1}{ }^{*}$ & 124.128 & 126.667 & 0.1471 & 0.15085 \\
& $T_{1}{ }^{*}$ & 0.11497 & 0.14454 & 7103.84 & 7305.21 \\
& $T I C_{1}{ }^{*}$ & 6827.06 & 6966.68 & 123.379 & 126.876 \\
& $Q_{1}{ }^{*}$ & 118.572 & 120.997 & 0.14116 & 0.14476 \\
& $T_{1}{ }^{*}$ & 0.11033 & 0.13871 & 7402.74 & 7612.59 \\
\hline
\end{tabular}

Table 2. (a) Values of optimal values of $Q=Q_{2} *, T=T_{2} *$ and $T I C=T I C_{2} *$ for different values of holding cost parameter ' $h$ ' and ordering cost ' $k$ ', taking all the elements constant as in example 2

\begin{tabular}{llllllll}
\hline$h$ & $Q_{2}{ }^{*}$ & $T_{2}{ }^{*}$ & $T I C_{2}{ }^{*}$ & $k$ & $Q_{2}{ }^{*}$ & $T_{2}{ }^{*}$ & $T I C_{2}{ }^{*}$ \\
\hline 15 & 1062.63 & 0.175537 & 4259.88 & 550 & 1255.66 & 0.202087 & 3969.79 \\
25 & 896.264 & 0.148262 & 5045.93 & 600 & 1292.61 & 0.213114 & 4207.75 \\
35 & 801.177 & 0.132638 & 5641.82 & 650 & 1327.56 & 0.218812 & 4439.26 \\
60 & 669.426 & 0.110949 & 6747.25 & 700 & 1360.76 & 0.224222 & 4664.96 \\
80 & 608.215 & 0.100855 & 7423.76 & 1000 & 1532.54 & 0.252161 & 5922.94 \\
\hline
\end{tabular}


Table 2. (b) Variation of optimal solution of $Q=Q_{2}{ }^{*}, T=T_{2}{ }^{*}$ and $T I C=T I C_{2} *$ with the variation of constant annual demand rate ' $\alpha$ ' and demand elasticity ' $\beta$ ', keeping all the parameters same as in example 2

\begin{tabular}{lllllll}
\hline$\alpha$ & $Q_{2}{ }^{*}$ & $T_{2}{ }^{*}$ & $T I C_{2}{ }^{*}$ & $\beta$ & $Q_{2}{ }^{*}$ & $T_{2}{ }^{*}$ \\
\hline 6100 & 1229.98 & 0.199603 & 3745.01 & 0.2 & 1216.27 & 0.198602 \\
6200 & 1243.28 & 0.198518 & 3765.22 & 0.3 & 1216.07 & 0.196517 \\
6300 & 1256.62 & 0.197474 & 3785.22 & 0.4 & 1215.77 & 3776.60 \\
6400 & 1269.88 & 0.196450 & 3805.01 & 0.5 & 1215.40 & 0.194417 \\
6500 & 1283.07 & 0.195447 & 3824.59 & 0.6 & 1214.94 & 0.192308 \\
\hline
\end{tabular}

\section{Conclusion and Future Research Directions}

In this study, we have extended Alfares (2007) model to allow for power demand rate with inventory dependent holding cost function and stock-dependent demand rate with time and inventory dependent holding cost function. Then, we have provided numerical examples for both models. In addition, we have presented the sensitivity analysis of key elements on the effect of the optimal solution. Results show that:

- $\quad$ An increase of ' $h$ ' leads decrease in $Q^{*}$ and $T I C^{*}$

- Increase of ' $\beta$ ' leads increase of order quantity and decrease in total inventory cost

- Increase of ordering cost leads increase in order quantity and total inventory cost

- Change in $\beta$ causes positive change in $T I C_{2} *$ and no change in $Q_{2}{ }^{*}$

- Change in $\alpha$ causes positive change in $Q_{2}{ }^{*}$ and $T I C_{2}{ }^{*}$

It is observed that changes are quite significant with the change of various system parameters. Second order approximations have been used for log arithmetic terms to find closed form optimal solution.

The models presented in this work can be extended in different ways. We may extend the demand as quadratic time dependent demand. The models can also be extended by adding for deteriorating items. In addition, the model can be generalized to allow for shortages and time value of money.

\section{Acknowledgement}

The authors are pleased to unknown reviewers for fruitful suggestions and valuable remarks and to the Editor-in-chief for handling of the holograph, which assisted to improve the presentation of the report.

\section{Funding Information}

The authors receive no financial backing or funding to report.

\section{Author's Contributions}

Rakesh Prakash Tripathi: Being a supervisor, he guided the student in the write-up, read through the manuscript, reviewed and approved it before sending to a journal.
Sarla Pareek: She guided the student in the preparation, reviewed and checked it before sending to a journal.

Manjit Kaur: Being a research student, she conceived the idea and drafted the paper.

\section{Ethics}

This article is original and contains unpublished material. There are no ethical issues involved in any aspect of this paper.

\section{References}

Alfares, H.K., 2007. Inventory model with stock-level dependent demand rate and variable holding cost. Int. J. Product. Econom., 108: 259-265.

DOI: $10.1016 /$ j.ijpe.2006.12.013

Baker, R.C. and T.L. Urban, 1988. A deterministic inventory system with an inventory-level-dependent demand rate. J. Operat. Res. Soc., 39: 823-831. DOI: 10.1057 /jors. 1988.142

Banerjee, A., 1986. A joint economic-lot-size model for purchaser and vendor. Decis. Sci., 17: 292-311. DOI: 10.1111/j.1540-5915.1986.tb00228.x

Chiang, C., 2001. Order splitting under periodic review inventory systems. Int. J. Prod. Res., 70: 67-76. DOI: $10.1016 / \mathrm{S} 0925-5273(00) 00046-3$

Chang, C.T., J.T. Teng and S.K. Goyal, 2010. Optimal replenishment policies for non-instantaneous deteriorating items with stock-dependent demand. Int. J. Product. Econom., 123: 62-68.

DOI: $10.1016 /$ j.ijpe.2009.06.042

Datta, T.K. and A.K. Pal, 1990. A note on an inventory model with inventory-level-dependent demand rate. J. Oper. Res. Soc., 41: 971-975. DOI: $10.2307 / 2583275$

Gerchak, Y. and Y. Wang, 1994. Periodic-review inventory models with inventory-level-dependent demand. Naval Res. Logistic, 41: 99-116.

DOI: $\quad 10.1002 / 1520-6750(199402) 41: 1<99:: A I D-$ NAV3220410107>3.0.CO;2-W

Ghiami, Y., T. Williams and Y. Wu, 2013. A twoechelon inventory model for a deteriorating item with stock-dependent demand, partial backlogging and capacity constraints. Eur. J. Operat. Res., 231: 587-597. DOI: 10.1016/j.ejor.2013.06.015 
Giri, B.C., A. Goswami and K.S. Chaudhuri, 1996. An EOQ model for deteriorating items with time varying demand and costs. J. Oper. Res., 47: 1398-1405. DOI: $10.2307 / 3010205$

Goyal, S.K. and C.T. Chang, 2009. Optimal ordering and transfer policy for an inventory with stock dependent demand. Eur. J. Operat. Res., 1996: 177-185. DOI: $10.1016 /$ j.ejor.2008.02.029

Goyal, S.K. and F. Nebebe, 2000. Determination of economic production-shipment policy for a singlevendor-single-buyer system. Eur. J. Operat. Res., 121: 175-178. DOI: 10.1016/S0377-2217(99)00013-2

Goyal, S.K., 1988. A Joint economic-lot-size model for purchaser and vendor: A comment. Decis. Sci., 19: 236-241. DOI: 10.1111/j.1540-5915.1988.tb00264.x

Gupta, R. and P. Vrat, 1986. Inventory model for stockdependent consumption rate. Opesearch, 23: 19-24.

Hill, R.M., 2000. On optimal two-stage lot sizing and inventory batching policies. Int. J. Product. Econom., 66: 149-158. DOI: 10.1016/S0925-5273(99)00122-X

Hou, K.L., 2006. An inventory model for deteriorating items with stock-dependent consumption rate and shortages under inflation and time discounting. Eur. J. Operat. Res., 168: 463-474.

DOI: $10.1016 /$ j.ejor.2004.05.011

Hwang, H. and K.H. Hahn, 2000. An optimal procurement policy for items with an inventory level-dependent demand rate and fixed lifetime. Eur. J. Operat. Res., 127: 537-545. DOI: $10.1016 / \mathrm{S} 0377-2217(99) 00337-9$

Jiangtao, M., C. Guimei, F. Teng and M. Hong, 2013. Optimal ordering policies for perishable multi-item under stock-dependent demand and two-level trade credit. Applied Math. Mod., 38: 2522-2532.

DOI: $10.1016 / \mathrm{j} . \mathrm{apm} .2013 .10 .058$

Law, S.T. and H.M. Wee, 2006. An integrated production-inventory model for ameliorating and deteriorating items taking account of time discounting. Math. Comp. Mode., 43: 673-685. DOI: $10.1016 / \mathrm{j} . \mathrm{mcm} .2005 .12 .012$

Levin, R.I., C.P. McLaughlis and R.P. Kottas, 1972. Production Operations Management: Contemporary Policy for Managing Operating Systems. 1st Edn., McGraw-Hill, New York, pp: 373.

Mandal, B.N. and S. Phanjdar, 1989. An inventory model for deteriorating items and stock-dependent demand rate. J. Operat. Res. Soc., 39: 823-831.

Padmanabhan, G. and P. Vrat, 1988. Inventory model for perishable items under stock dependent consumption rate. Proceedings of the XXBI-Annual ORSI Convention, (SIC' 88), Trivandrum, India.
Pal, S., A. Goswami and K.S. Chaudhuri, 1993. A deterministic inventory model for deteriorating items with stock-dependent demand rate. Int. J. Product. Econom., 32: 291-299. DOI: 10.1016/0925-5273(93)90043-K

Ray, J. and K.S. Chaudhuri, 1997. An EOQ model with stock-dependent demand, shortage, inflation and time discounting. In. J. Product. Econom., 53: 171-180. DOI: $10.1016 / \mathrm{S} 0925-5273(97) 00112-6$

Siajadi, H., R.N. Ibrarahim and P.B. Locher, 2006. A single-vendor multiple-buyer inventory model with a multiple-shipment policy. Int. J. Adv. Manu. Tech., 27: 1030-1037. DOI: 10.1007/s00170-004-2267-4

Silver, E.A. and R. Peterson, 1985. Decision Systems for Inventory Management and Production Planning: Solutions Manual. 2nd Edn., John Wiley and Sons Australia, Limited, ISBN-10: 0471818143, pp: 493.

Soni, H.N., 2013. Optimal replenishment policies for non-instantaneous deteriorating items with price and stock sensitive demand under permissible delay in payment. Int. J. Product. Econom., 146: 259-268. DOI: 10.1016/j.ijpe.2013.07.006

Teng, J.T., I.P. Krommyada, K. Skouri and K.R. Lou, 2011. A comprehensive extension of optimal ordering policy for stock-dependent demand under progressive payment scheme. Eur. J. Operat. Res., 215: 97-104. DOI: 10.1016/j.ejor.2011.05.056

Urban, T.L., 1995. Inventory models with the demand rate dependent on stock and shortage levels. Int. J. Product. Econom., 40: 21-28. DOI: 10.1016/0925-5273(95)00036-N

Viswanathan, S., 1998. Optimal strategy for the integrated vendor-buyer inventory model. Eur. J. Operat. Res., 105: 38-42. DOI: $10.1016 / \mathrm{S} 0377-2217(97) 00032-5$

Yang, C.T., 2014. An inventory model with both stockdependent demand rate and stock-dependent holding cost rate. Int. J. Product. Econom., 155: 214-221. DOI: 10.1016/j.ijpe.2014.01.016

Yang, H.L., J.T. Tang and M.S. Chen, 2010. An inventory model under inflation for deteriorating items with stock-dependent consumption rate and partial backlogging shortages. Int. J. Product. Econom., 123: 8-19. DOI: 10.1016/j.ijpe.2009.06.041

Yang, P.C. and H.M. Wee, 2003. An integrated multilot-size production inventory model for deteriorating item. Comput. Operat. Res., 30: 671-682.

DOI: 10.1016/S0305-0548(02)00032-1 